\title{
Socioeconomic Variables Effecting Female Sexual Function in an Urban, Community Setting
}

\author{
Krista L. Neal ${ }^{1}$, Stephanie Teng1, Mazvita Nyamukapa ${ }^{1}$, Victoria Greenberg', \\ Alexis Braverman'1, Brett Worly ${ }^{2 *}$ \\ ${ }^{1}$ Department of Obstetrics and Gynecology, Thomas Jefferson University Hospital, Philadelphia, USA \\ ${ }^{2}$ Department of Obstetrics and Gynecology, The Ohio State University Wexner Medical Center, Columbus, \\ USA \\ Email: Brett.worly@osumc.edu
}

Received 13 March 2015; accepted 28 March 2015; published 31 March 2015

Copyright (C) 2015 by authors and Scientific Research Publishing Inc.

This work is licensed under the Creative Commons Attribution International License (CC BY). http://creativecommons.org/licenses/by/4.0/

(c) (i) Open Access

\begin{abstract}
Introduction: Female sexual dysfunction is a common problem affecting $12 \%-63 \%$ of the population, and its relationship with demographic factors, depression, and urinary incontinence needs to be more clearly identified. Aims: To determine demographic and clinical conditions associated with female sexual dysfunction in an urban population of women seeking routine gynecologic care. Methods: A cross-sectional, IRB approved study with a convenience sample was performed of 238 sexually-active, non-pregnant women reporting to two urban gynecology clinics: a private practice ( $n=168$ ) and a publicly funded ambulatory clinic $(n=70)$. Main Outcome Measures: The participants completed informed consent and a demographic questionnaire, plus validated questionnaires that measured sexual function with the Female Sexual Function Index (FSFI), depression with the Center for Epidemiologic Studies Depression Scale (CES-D), and urinary incontinence with the Questionnaire for Urinary Incontinence Diagnosis (QUID). Results: The mean FSFI score for those with public insurance and private insurance was $29.5 \pm 4.2$ and $27.8 \pm 5.1$ (OR 0.746, p = $0.0005,95 \%$ CI 0.633, 0.881) respectively. In comparing "private" and "public" patient groups, age, weight, race, education, employment, exercise, household income, smoking, alcohol frequency, and sex frequency were all significantly different $(p<0.05)$. Multivariate logistic regression analysis found that female sexual dysfunction correlated with less education (OR 1.379, p = 0.0346, 95\% CI $1.024,1.858$ ), and worsening depression identified by CES-D score (OR $1.088, p<0.0001,95 \%$ CI 1.043, 1.135). Conclusions: Female sexual dysfunction was associated with decreased household income, urinary incontinence, less education, and depression.
\end{abstract}

${ }^{*}$ Corresponding author.

How to cite this paper: Neal, K.L., Teng, S., Nyamukapa, M., Greenberg, V., Braverman, A. and Worly, B. (2015) Socioeconomic Variables Effecting Female Sexual Function in an Urban, Community Setting. Open Journal of Obstetrics and Gynecology, 5, 195-202. http://dx.doi.org/10.4236/ojog.2015.54028 
Keywords

Sexual Dysfunction, Socioeconomic Factors, Depression, Education, Urinary Incontinence

\section{Introduction}

Sexual dysfunction in females is a common problem, with reported prevalence rates of $40 \%$, but can range from $12 \%$ - 63\% depending on the measurement technique and type of dysfunction measured [1]-[6]. Female sexual dysfunction is defined as a disturbance in sexual desire and psycho-physiological sexual performance with emotional distress [7] [8]. The normal sexual response in women is described by several models and disturbance at any point can lead to sexual dysfunction and anxiety [6] [9]-[15]. Sexual health is multifaceted and encompasses physical, emotional, mental, and social well-being [16]. Sexual health is an important moiety in overall physical and emotional wellness, but is often not thoroughly evaluated by health care providers at routine visits for multiple reasons, including patient and provider embarrassment regarding a sensitive topic [17]. Specific risk factors for female sexual dysfunction have been previously reported, and include age, general stress, urinary tract problems including incontinence, depression, poly-pharmacy, and declining income [1]-[6] [18] [19]. Previous work did not use validated sexual function, urinary incontinence, and depression questionnaires simultaneously in looking at the impact of socioeconomic and cultural variables on female sexual function.

\section{Methods}

A descriptive cross-sectional study with a convenience sample was performed. The study was approved by the Institutional Review Board of Thomas Jefferson University (TJU). We recruited women from their respective outpatient waiting rooms in the "private" group office and the "public" group clinic at TJU, located in Philadelphia, Pennsylvania. Study personnel were trained at recruitment by the Primary Investigator (BW), and no compensation was given to participants. Written, informed consent was obtained. This study was registered at ClinicalTrials.gov. A total of 320 women were enrolled between February 2011 and August 2012, including 221 women from the "private" group and 99 women from the "public" group. To detect a $30 \%$ difference in sexual dysfunction between the two populations at a power of 0.80 and an alpha of 0.05 , we estimated a sample size of 375 women.

Our study aims to compare two populations of women in an urban community setting with separate socioeconomic profiles to identify factors associated with female sexual function. Participants who are or are not medically underserved were examined in an attempt to describe an association between socioeconomic status and sexual dysfunction. One population includes privately insured patients from a private group practice staffed by attending physicians, the "private" group. The "public" group includes underserved, Medicaid patients with publicly funded or Family Planning grant funded care from an ambulatory clinic staffed by both attending and resident physicians. This study investigates the link between sexual dysfunction, depression, urinary incontinence, socioeconomic status, type of health insurance, as well as other demographic factors in these two patient populations. A higher prevalence of sexual dysfunction is hypothesized in the underserved population due to stressors from lower socioeconomic status, lack of education, and unemployment. Secondly, we hypothesized that sexual dysfunction would be positively associated with depression and urinary incontinence in both groups.

Our inclusion criteria for subjects were women age 18 or older, presenting for an annual routine gynecology appointment, and were sexually active in the past six months. Our exclusion criteria were pregnant women, women who were less than six weeks post-partum, women reporting for a gynecologic problem visit, non-English speakers, incomplete survey questionnaires, or refusal to consent to participate in the study. Twenty-nine women were excluded from the "public" group (29\%), and 53 women from the "private" group (24\%) were excluded based on the exclusion criteria. The most common reason for excluding participation in the "private" group was "no sexual activity" on the FSFI questions 3 - 14, or 17 - 19, with 72\% (38/53) of "private" participants excluded for this reason. The most common excluding factor in the "public" group was "no sexual activity" on the FSFI questions 3 - 14 or 17 - 19, with 59\% (17/29) of "public" participants excluded for this reason. One "public" participant may have had literacy problems, as she had four random answers that were "no sexual activity" on the FSFI, while the remainder of her answers seemed plausible. This subject was included in analysis 
in the "public" group.

We surveyed our participants with five different questionnaires. We established demographic information with a non-validated multiple choice Health Information Survey (HIS) that measured age, race, religion, smoking, history of depression, medication use, education, household income, exercise, and employment status [1]. Age and weight were written onto the survey by participants, and recorded as continuous variables. The remaining HIS items were categorized and coded as seen in Table 1, in a multiple choice format.

The participants then took the Female Sexual Function Index (FSFI), a self-reported nineteen-item questionnaire that indicates risk for sexual dysfunction in participants who scored lower than 27 out of 36 points [20] [21]. The FSFI was altered to include patients who were sexually active in the last 6 months in order to obtain an appropriate sample size for comparison of the two groups. "Distress" was not assessed in regards to sexual function, as the diminished sample size of those with sexual dysfunction would have made analysis increasingly difficult. Depression in subjects was assessed using the Center for Epidemiologic Studies Depression Scale (CESD); scores above or equal to 16 were indicative of the presence of depression [22]. Lastly, we measured both stress and urge incontinence with the six-item Questionnaire for Urinary Incontinence Diagnosis (QUID), in which a score of 6 or more indicates incontinence [23]. The FSFI, CES-D, and QUID are all internally and externally validated surveys [20]-[23]. The four surveys took each participant approximately 30 - 45 minutes to complete. Greater than $90 \%$ of participants completed all surveys. The survey answers were coded and patient information de-identified for analysis.

The demographic data were described using means and percentages. Continuous variables including age, weight, household income, duration of education, alcohol frequency, number of medicines taken daily, sex frequency, CES-D scores, QUID scores, and FSFI scores were compared using parametric Student t-tests. Categorical data, such as race, clinic groups, female sexual dysfunction (defined by FSFI < 27), and cigarette smoking were compared using the chi-squared test and Fisher exact test, when appropriate. In addition, we performed a univariate linear regression analysis and Pearson correlations for all of the above variables. A $p<0.05$ was considered statistically significant for primary outcome data. Bonferroni correction was used for secondary outcomes due to the large number of variables assessed. The p value 0.05 was divided by a total of 50 questions on the HIS, therefore on linear regression analysis of the HIS responses, $\mathrm{p}<0.001$ was considered significant. Multivariate regression analysis was performed for FSFI score, clinic group, CES-D score, household income, race, age, QUID score, and education duration. All statistics were completed using STATA version 9.2 (Stata Corp, College Station, TX).

\section{Main Outcome Measures}

The primary outcome measures of this study include Female Sexual Function as measured by the FSFI, depression as measured by the CES-D, urinary incontinence as measured by the QUID, and demographic variables including age, race, education, and household income. Secondary outcome measures included the remainder of the HIS. Secondary analysis of our data combined both groups to better understand important factors effecting female sexual function in an urban setting.

\section{Results}

We recruited women in both clinics from June 2011 through August 2012; 320 women chose to participate in the study, out of 619 women approached (52\% recruitment success). As previously described, the remaining 238 women were included in the statistical analysis.

The demographic data for the participants in both populations are shown in Table 1. The mean age of women in the public insurance group was $26.9 \pm 6.6$ years, while in the private insurance group the mean age was $36.3 \pm$ 12.1 years. The subjects in the "public" group were more likely to be young, African American, and report a yearly household income less than forty thousand dollars. Women in the "private" group were more likely to be older, Caucasian, and have a reported household income of more than forty thousand per year. In addition, only $48.6 \%$ of the "public" group reported having a college degree or trade school education, in contrast to $91.5 \%$ of women in the "private" group reported a college degree. Employment rates between the two groups were different, with the "private" group population being slightly higher at $82.1 \%$ versus $62.9 \%$ for women from the "public" group. The "private" and "public" groups showed a significant difference related to the frequency of smoking, exercise, alcohol consumption, and sexual inactivity. Overall, the two populations of women 
Table 1. Several demographic factors of sexually active women with public and private health insurance. Demographic data values are given as number (percentage) or mean \pm standard deviation unless otherwise indicated.

\begin{tabular}{|c|c|c|c|}
\hline & Public Insurance N = 70 & Private Insurance N = 168 & $\mathrm{p}$ value \\
\hline Age (years) & $26.9 \pm 6.6$ & $36.3 \pm 12.1$ & $<0.0001$ \\
\hline Weight (pounds) & $161.8 \pm 20.5$ & $144.9 \pm 30.6$ & 0.0024 \\
\hline $\begin{array}{c}\text { Race } \\
\text { Caucasian } \\
\text { African American } \\
\text { Asian } \\
\text { Hispanic/Latino } \\
\text { Other }\end{array}$ & $\begin{array}{c}12(17.4) \\
46(66.7) \\
5(7.2) \\
1(1.5) \\
5(7.2)\end{array}$ & $\begin{array}{c}120(72.3) \\
29(17.5) \\
4(2.4) \\
9(5.4) \\
4(2.4)\end{array}$ & 0.012 \\
\hline $\begin{array}{c}\text { Education } \\
\text { HS/GED or Less } \\
2 \text { year College/Trade } \\
4 \text { years College } \\
\text { Graduate School }\end{array}$ & $\begin{array}{c}36(51.5) \\
19(27.1) \\
14(20) \\
1(1.4)\end{array}$ & $\begin{array}{c}14(8.5) \\
18(10.8) \\
76(45.8) \\
58(34.9)\end{array}$ & $<0.0001$ \\
\hline $\begin{array}{c}\text { Employment } \\
\text { Yes/Part-time } \\
\text { No }\end{array}$ & $\begin{array}{l}44(62.9) \\
26(37.1)\end{array}$ & $\begin{array}{c}138(82.1) \\
30(17.9)\end{array}$ & 0.02 \\
\hline $\begin{array}{c}\text { Household Income, US\$ } \\
<20,000 \\
20,000-40,000 \\
40,000-80,000 \\
>80,000\end{array}$ & $\begin{array}{c}32(45.7) \\
24(34.3) \\
7(10) \\
1(1.4)\end{array}$ & $\begin{array}{l}17(10.4) \\
22(13.5) \\
43(26.4) \\
81(49.7)\end{array}$ & $<0.0001$ \\
\hline $\begin{array}{c}\text { Exercise Regularly } \\
\text { Yes } \\
\text { No }\end{array}$ & $\begin{array}{l}34(48.6) \\
36(51.4)\end{array}$ & $\begin{array}{c}120(72.3) \\
46(27.7)\end{array}$ & 0.0004 \\
\hline $\begin{array}{c}\text { Prescriptions/OTC } \\
\text { None } \\
1-3 \\
>4\end{array}$ & $\begin{array}{l}48(68.6) \\
19(27.1) \\
3(4.3)\end{array}$ & $\begin{array}{c}67(39.9) \\
86(51.2) \\
15(8.9)\end{array}$ & 0.0002 \\
\hline $\begin{array}{c}\text { Cigarette Smoking } \\
\text { Yes } \\
\text { No }\end{array}$ & $\begin{array}{l}15 \text { (21.7) } \\
54(78.3)\end{array}$ & $\begin{array}{c}13(7.7) \\
155(92.3)\end{array}$ & 0.01 \\
\hline $\begin{array}{l}\text { Alcohol Frequency } \\
\text { Less than } 1 \text { per month } \\
\text { Greater than } 1 \text { per month }\end{array}$ & $\begin{array}{l}47 \text { (69.1) } \\
21(30.9)\end{array}$ & $\begin{array}{c}53(31.5) \\
115(68.5)\end{array}$ & $<0.0001$ \\
\hline $\begin{array}{l}\text { Sex Frequency } \\
1 \text { or more per day } \\
2 \text { - } 6 \times \text { per week } \\
1 \times \text { per week } \\
1 \text { - } 3 \times \text { per month } \\
5 \text { - } 10 \times \text { per year } \\
1 \text { - } 4 \times \text { per year }\end{array}$ & $\begin{array}{l}14(20.9) \\
22(32.8) \\
17(25.4) \\
12(17.9) \\
1(1.5) \\
1(1.5)\end{array}$ & $\begin{array}{c}5(2.9) \\
50(29.8) \\
64(38.1) \\
30(17.9) \\
10(5.9) \\
9(5.4)\end{array}$ & 0.0003 \\
\hline FSFI Score (Dysfunction < 26.55) & $29.5 \pm 4.2,17(24.3)$ & $27.8 \pm 5.1,62(36.9)$ & $0.0172^{*}$ \\
\hline CESD Score (Depression > 16) & $13.5 \pm 10.7,21(31.8)$ & $10.8 \pm 8.9,40(24.5)$ & 0.05 \\
\hline UI Score (Incontinence > 6) & $2.9 \pm 4.7,11(17.2)$ & $3.02 \pm 4.5,30(18.1)$ & 0.92 \\
\hline Prevalence of Female Sexual Dysfunction & 17 (24.3) & 62 (36.9) & 0.03 \\
\hline
\end{tabular}

*To compare the populations we examined skewness and Kurtosis. For the "public" group, the skewness was -0.4769 and Kurtosis was -0.7303 , and the distribution did not deviate significantly from normal by the Kolmogorov-Smirnov criterion D $=0.0912$, $\mathrm{Pr}>\mathrm{D}>0.1500$. However, Clinic $=2$ had skewness $=-0.8819$ and Kurtosis $=0.3342$, which deviated significantly from normal, $\mathrm{D}=0.1264, \operatorname{Pr}>\mathrm{D}<0.0100$. We therefore compared the populations using the non-parametric Wilcoxon test. This test yielded Wilcoxon statistic of 9389.5, $\mathrm{Z}=2.1160$, one-sided $\mathrm{Pr}=0.0172$ (we had a directional hypothesis on this comparison). The Two-Sided $\mathrm{Pr}$ value $(\mathrm{Pr}=0.0343)$ is also significant at the 0.05 level. $\mathrm{Z}$ includes a continuity correction of 0.5 .

were significantly different in several other key demographic factors, including age, race, and household income (Table 1).

Sexual function was measured with the FSFI scale, which generates an overall sexual function score, subdi- 
vided into 6 categories of function: desire, arousal, lubrication, orgasm, satisfaction, and pain. Using the previously validated cut-off score of 27 for the overall scale, there is a $24.3 \%$ prevalence of patients at risk for sexual dysfunction in the "public" group, and 36.9\% dysfunction in the "private" group, which reaches statistical significance $(\mathrm{p}<0.05)$. Figure 1 shows the FSFI subcategory scores for each group. The "private" group had statistically significant decreased scores in overall sexual function, and the subtypes desire, satisfaction, and pain as indicated by the FSFI on linear regression analysis. The mean FSFI score in the "public" group was $29.5 \pm$ 4.2 compared to $27.8 \pm 5.1$ in the "private" group. Both patient populations have a moderate level of sexual dysfunction in all categories, which is similar to the reported prevalence in the general population [1]-[6].

The data from the public and private insurance groups was pooled for portions of the following analyses, to obtain a better representative sample size of all patients presenting for GYN well-care at our urban, community, university-based practice.

\section{Socioeconomic Factors}

The association between sexual dysfunction and socioeconomic variables was assessed. Socioeconomic status was measured using variables of age, race, education level, employment status, and reported income (Table 1). In the two groups combined, women with a reported household income of twenty thousand or less per year ( $\mathrm{n}=$ 49) had a $42.9 \%$ prevalence of sexual dysfunction. The percent of women with sexual dysfunction in households with income of one hundred thousand or more per year $(n=57)$ was significantly lower, at $22.83 \%$. These data suggest that a greater yearly income was associated with a lower incidence of sexual dysfunction in this urban population $(\mathrm{p}<0.05)$. Other variables including religion, parity, partner availability and sexual function, chronic hypertension, diabetes, hormonal status, and oral contraceptive pill use were assessed by the HIS, and no statistically significant differences were found in the participant groups (data not shown).

Table 2 examines factors affecting female sexual function as rated by the FSFI score within all subjects and subgroups that include those patients with publicly- or privately-funded insurance, and Caucasian and African American races. Pearson correlation coefficients are included as "r" values, where a positive $r$ value indicates a positive correlation, and a negative $r$ value indicates an inverse correlation. Race and clinic population were not associated with sexual function on linear regression analysis. Table 2 is notable for associations between a worsening FSFI score and depression as rated by the CES-D, household income, urinary incontinence (QUID score), and all subclasses of Sexual Dysfunction as rated by the FSFI. Diabetes, chronic hypertension, and polypharmacy ( $>4$ medicines), hormone replacement therapy, and hormonal contraception including oral contraceptive pills were not associated with female sexual dysfunction.

We measured a prevalence of $40 \%$ sexual dysfunction in women with a high school degree or less $(n=50)$, while women with a college degree $(n=186)$ measured a prevalence of $31.2 \%$ sexual dysfunction. Those with

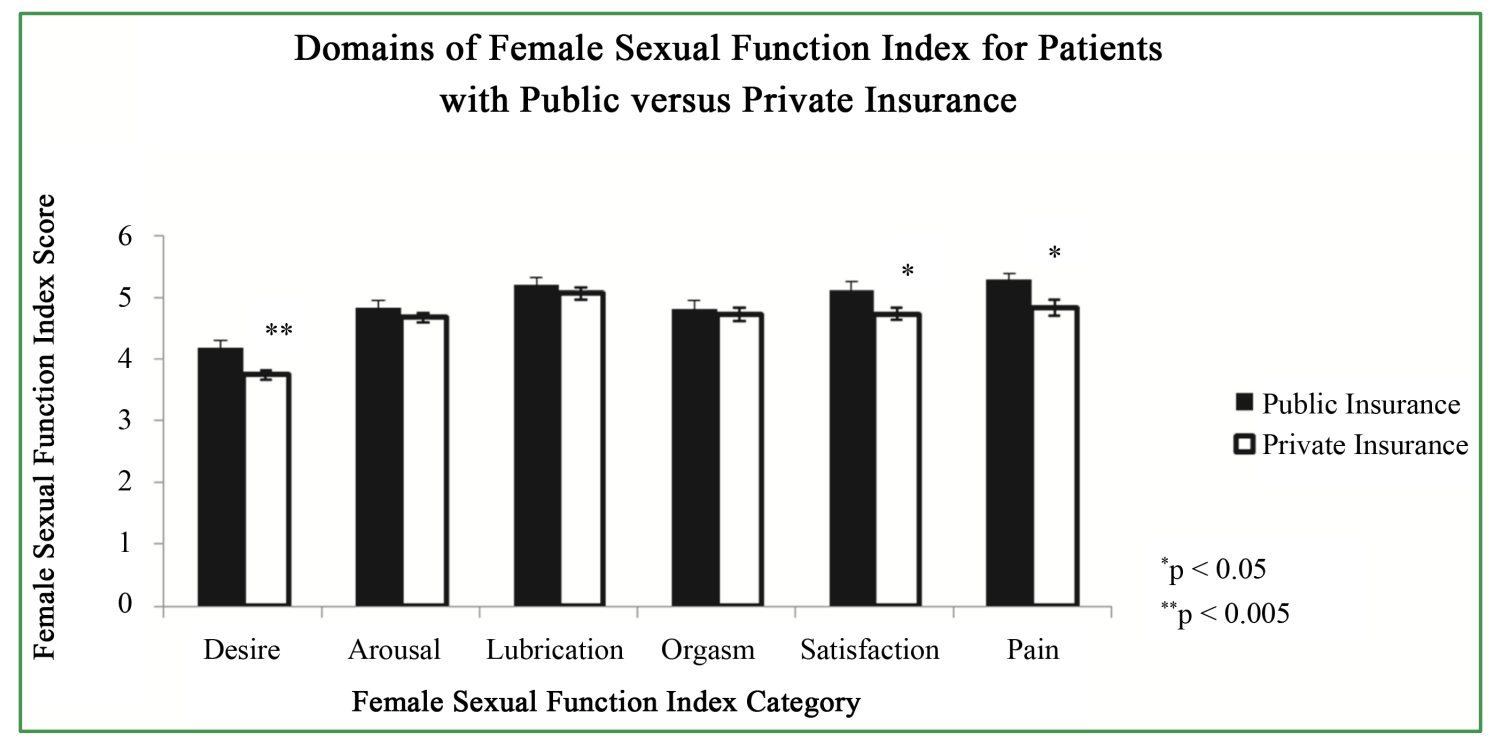

Figure 1. Sub-domains of the female sexual function index for patients with public and private health insurance. 
Table 2. Linear regression analysis performed examining the influence of characteristics in the left column on FSFI score, within the individual groups in the top row. Regression coefficients ( $r$ ) are included where statistically significant $(p<0.001)$, and (NS) suggests not statistically significant $(\mathrm{p}>0.001)$. A positive $\mathrm{r}$ value suggests a positive correlation, while a negative r value suggests an inverse correlation.

\begin{tabular}{cccccc}
\hline & $\begin{array}{c}\text { All subjects } \\
(\mathrm{n}=238)\end{array}$ & $\begin{array}{c}\text { Public Insurance } \\
(\mathrm{n}=70)\end{array}$ & $\begin{array}{c}\text { Private Insurance } \\
(\mathrm{n}=168)\end{array}$ & $\begin{array}{c}\text { Caucasian }(\mathrm{n}= \\
132)\end{array}$ & $\begin{array}{c}\text { African American } \\
(\mathrm{n}=75)\end{array}$ \\
\hline Desire (FSFI) & $\mathrm{r}=0.55$ & $\mathrm{r}=0.46$ & $\mathrm{r}=0.51$ & $\mathrm{r}=0.60$ & $\mathrm{r}=0.45$ \\
Arousal (FSFI) & $\mathrm{r}=0.80$ & $\mathrm{r}=0.82$ & $\mathrm{r}=0.80$ & $\mathrm{r}=0.82$ & $\mathrm{r}=0.80$ \\
Lubrication (FSFI) & $\mathrm{r}=0.70$ & $\mathrm{r}=0.74$ & $\mathrm{r}=0.74$ & $\mathrm{r}=0.70$ & $\mathrm{r}=0.75$ \\
Orgasm (FSFI) & $\mathrm{r}=0.69$ & $\mathrm{r}=0.72$ & $\mathrm{r}=0.70$ & $\mathrm{r}=0.72$ & $\mathrm{r}=0.60$ \\
Satisfaction (FSFI) & $\mathrm{r}=0.71$ & $\mathrm{r}=0.69$ & $\mathrm{r}=0.69$ & $\mathrm{r}=0.68$ & $\mathrm{r}=0.71$ \\
Pain (FSFI) & $\mathrm{r}=0.61$ & $\mathrm{r}=0.52$ & $\mathrm{r}=0.61$ & $\mathrm{r}=-0.62$ & $\mathrm{NS}$ \\
CES-D Score & $\mathrm{r}=-0.36$ & $\mathrm{r}=-0.50$ & $\mathrm{r}=-0.35$ & $\mathrm{NS}$ & $\mathrm{r}=-0.30$ \\
QUID Sum & $\mathrm{r}=-0.17$ & $\mathrm{NS}$ & $\mathrm{r}=-0.18$ & $\mathrm{NS}$ & $\mathrm{N}$ \\
Household Income & $\mathrm{NS}$ & $\mathrm{r}=0.31$ & $\mathrm{r}=0.24$ & $\mathrm{NS}$ & $\mathrm{NS}$ \\
Education & $\mathrm{NS}$ & $\mathrm{NS}$ & $\mathrm{r}=0.19$ & & \\
\hline
\end{tabular}

good sexual function showed an association with increasing amounts of education on multivariate logistic regression analysis (OR 1.379, $\mathrm{p}=0.0346,95 \%$ CI 1.024, 1.858). Employment status was not associated with sexual function in this analysis. Multivariate logistic regression also found an association between depression found on the CES-D and sexual dysfunction (OR 1.088, p < 0.0001, 95\% CI 1.043, 1.135). In these populations, the prevalence of depression, based on CES-D scores, was significantly higher in the "public" group, 31.8\%, versus $24.5 \%$ in "private" group (Table 1 ).

Multivariate logistic regression analysis of "private" versus "public" group comparison suggests age (OR 1.089, $\mathrm{p}=0.0391,95 \%$ CI 1.004, 1.181), education (OR 3.022, $\mathrm{p}<0.0001,95 \%$ CI 1.814, 5.035), FSFI score (OR 0.746, p $=0.0005,95 \%$ CI 0.633, 0.881), and household income (OR 3.124, p $=0.0009,95 \%$ CI 1.598, 6.110) were all significantly different between the two groups. Clinic group was not a predictor of sexual dysfunction on multivariate analysis after controlling for age. In comparing those patients with sexual function to those patients with sexual dysfunction by multivariate logistic regression analysis, education (OR 1.379, $\mathrm{p}=$ 0.0346, 95\% CI 1.024, 1.858), and CESD score (OR 1.088, $\mathrm{p}<0.0001,95 \%$ CI 1.043, 1.135) were the only variables found to be significantly different.

\section{Discussion}

Our hypothesis that women of lower socioeconomic status would have a higher incidence of female sexual dysfunction was found incorrect in this study. Women from the "private" clinic had a higher prevalence of sexual dysfunction, likely due to the confounder of age. When all patients were evaluated together with multifactorial analysis, the factors most associated with female sexual dysfunction were less education, and worse depression score.

The prevalence of sexual dysfunction was $37 \%$ among women in the "private” group. Women in this group were generally older, Caucasian, highly-educated, and reported a higher income level. The prevalence of sexual dysfunction was $24 \%$ among women in the "public" group. Women in this group were generally young African-Americans with a lower education level and low annual income. Contrary to our hypothesis, a higher prevalence of sexual dysfunction was found in the private-insurance population with the Student t test, with specific dysfunction in desire, satisfaction, and pain. This result may be due to the increased age or other unknown factors of women in the "private" group, rather than reflective of socioeconomic factors in that population. However, in linear regression analysis of the two groups, household income, not age, was more closely related to female sexual function, based on the FSFI. Those with higher household incomes in the "public" and "private" groups had better sexual function on the FSFI based on linear regression analysis. The association of increased sexual dysfunction with decreased household income indicates the need for physicians to take care to screen this 
specific population for sexual dysfunction, especially in the implicated categories of desire, satisfaction, and pain for older patients.

Other important findings are the identification of several conditions associated with sexual dysfunction including increased age, Hispanic or African American race, education status of a high school diploma or less, unemployment, depression as indicated by the CES-D, or those with any subtype of Female Sexual Dysfunction noted on the FSFI are more likely to have sexual dysfunction. Many of these risk factors confirm previous findings in other related studies, outlining their importance and strong association across diverse populations [1]-[6].

This study is unique in its focus on determining female sexual dysfunction in an urban, diverse community population with well-validated instruments, including the FSFI, CES-D, demographic factors, and QUID. An additional strength of this study is the vivid reflection of different socioeconomic demographics between the public-insurance population and the private-insurance population. Women who sought care at the public-insurance clinic were predominantly younger (median age $=26$ ), African-American $(67 \%)$, with less education and lower annual income; while women who sought care at the private practice were predominantly older (median age $=32$ ), Caucasian $(72 \%)$, more highly educated, and with greater annual income. This inherent difference in demographics between the two patient populations increases the likelihood that confounding variables impact the data analysis and results. However, the strong inherent demographic differences between the two populations should serve to remind healthcare providers to be mindful of the disparity of their diverse patient populations and the impact of socioeconomic factors on patients' health and the healthcare system overall. Healthcare provider experience, age, and training are unlikely to have confounded the results, as participants were given objective, validated questionnaires, before they saw the health care provider.

A unique barrier to completing this research was patient recruitment, particularly in the "public" group population. This difficulty in recruitment resulted in a large discrepancy between the number of private-insurance and public-insurance subjects, which may affect the external validity of the results. Selection bias also existed, possibly making those with poor sexual function less likely to participate because of their insecurity about this difficult issue, or more likely to participate due to their potential embarrassment regarding this issue, and a clear venue to communicate their problem. External validity may be quite strong, as these patients provide a good representation of patients with publicly-funded insurance seeking Gynecologic annual exams. Future studies can attempt to circumvent this barrier by extending the time duration of patient recruitment in hopes of increasing the pool of potential qualifying patients.

A few other aspects of our study design may also limit the external validity of our results. One of these was the exclusion of women who were not sexually active. This criterion possibly excluded women who chose to be sexually inactive because of their sexual dysfunction (e.g. lack of desire, pain). In addition, since recruitment of patients occurred in health care offices and included only women reporting for a routine gynecological visit, these findings may not relate to all women or women that do not regularly see a gynecologist. Finally, the study is limited by the cross-sectional convenience sample design, which allows for associations to be understood, but does not allow any causal relationships to be drawn.

\section{Conclusion}

Overall, this study has identified key health and social factors that are associated with female sexual dysfunction in two urban populations of women. We found that women with depression on the CESD and less than a high school education were more likely to have sexual dysfunction. These findings are useful for healthcare providers who wish to successfully target and screen high-risk populations to identify women with sexual dysfunction or to evaluate therapies for sexual dysfunction.

\section{Acknowledgements}

Funding for Open Access provided by The Ohio State University Open Access Fund.

\section{References}

[1] Worly, B., Gopal, M. and Arya, L. (2010) Sexual Dysfunction among Women of Low-Income Status in an UrbanSetting. International Journal of Gynecology \& Obstetrics, 111, 241-244. http://dx.doi.org/10.1016/j.ijgo.2010.06.019

[2] Laumann, E.O., Paik, A. and Rosen, R. (1999) Sexual Dysfunction in the United States: Prevalence and Predictors. JAMA, 281, 537-544. http://dx.doi.org/10.1001/jama.281.6.537 
[3] Shifren, J., Monz, B., Russo, P., Segreti, A. and Johannes, C. (2008) Sexual Problems and Distress in United States Women: Prevalence and Correlates. Obstetrics \& Gynecology, 112, 970-978. http://dx.doi.org/10.1097/AOG.0b013e3181898cdb

[4] Jiann, B.P., Su, C.C., Yu, C.C., Wu, T. and Huang, J.K. (1999) Risk Factors for Individual Domains of Sexual Function. The Journal of Sexual Medicine, 6, 3364-3375. http://dx.doi.org/10.1111/j.1743-6109.2009.01494.x

[5] Frank, E., Anderson, C. and Rubinstein, D. (1978) Frequency of Sexual Dysfunction in "Normal” Couples. The New England Journal of Medicine, 299, 111-115. http://dx.doi.org/10.1056/NEJM197807202990302

[6] Masters, W. and Johnson, V. (1966) Human Sexual Response. Little, Brown, Boston.

[7] American Psychiatric Assoc. (2000) Diagnostic and Statistical Manual of Mental Disorders. 4th Edition, Text Revision. Washington DC, 535 p.

[8] Bancroft, J., Loftus, J. and Long, J. (2003) Distress about Sex: A National Survey of Women in Heterosexual Relationships. Archives of Sexual Behavior, 32, 193-208. http://dx.doi.org/10.1023/A:1023420431760

[9] Kaplan, H. (1979) Disorders of Sexual Desire and Other New Concepts and Techniques in Sex Therapy. Brunner/ Hazel Publications, New York.

[10] Berman, J. and Bassuk, J. (2002) Physiology and Pathophysiology of Female Sexual Function and Dysfunction. World Journal of Urology, 20, 111-118. http://dx.doi.org/10.1007/s00345-002-0281-4

[11] Working Group on a New View of Women’s Sexual Problems (2000) A New View of Women's Sexual Problems. Electronic Journal of Human Sexuality, 3. www.ejhs.org/volume3/newview.htm

[12] Whipple, B. (2002) Women's Sexual Pleasure and Satisfaction. A New View of Female Sexual Function. The Female Patient, 27, 39-44.

[13] Basson, R. (2001) Female Sexual Response: The Role of Drugs in the Management of Sexual Dysfunction. Obstetrics \& Gynecology, 98, 350-353. http://dx.doi.org/10.1016/S0029-7844(01)01452-1

[14] Whipple, B. and Brash-McGreer, K. (1997) Management of Female Sexual Dysfunction. In: Sipski, M.L. and Alexander, C.J., Eds., Sexual Function in People with Disability and Chronic Illness. A Health Professional's Guide, Aspen Publishers, Inc., Gaithersburg, 509-534.

[15] Sand, M. and Fisher, W.A. (2007) Women’s Endorsement of Models of Female Sexual Response: The Nurses’ Sexuality Study. The Journal of Sexual Medicine, 4, 708-719. http://dx.doi.org/10.1111/j.1743-6109.2007.00496.x

[16] World Health Organization (2012) Sexual Health. http://www.who.int/topics/sexual_health/en/

[17] Marwick, C. (1999) Survey Says Patients Expect Little Physician Help on Sex. JAMA, 281, 2173-2174. http://dx.doi.org/10.1001/jama.281.23.2173

[18] Avis, N., Zhao, X., Johannes, C., Ory, M., Brockwell, S. and Greendale, G. (2005) Correlates of Sexual Function among Multi-Ethnic Middle-Aged Women: Results from the Study of Women's Health Across the Nation (SWAN). Menopause, 12, 385-398. http://dx.doi.org/10.1097/01.GME.0000151656.92317.A9

[19] Rogers, R.G., Kammerer-Doak, D., Villarreal, A., Coates, K. and Qualls, C. (2001) A New Instrument to Measure Sexual Function in Women with Urinary Incontinence or Pelvic Organ Prolapse. American Journal of Obstetrics and Gynecology, 184, 552-558. http://dx.doi.org/10.1067/mob.2001.111100

[20] Rosen, R., Brown, C., Heiman, J., Leiblum, S., Meston, C., Shabsigh, R., Ferguson, D. and D’agostino, R. (2000) The Female Sexual Function Index (FSFI): A Multi-Dimensional Self-Report for the Assessment of Female Sexual Function. Journal of Sex \& Marital Therapy, 26, 191-208. http://dx.doi.org/10.1080/009262300278597

[21] Wiegel, M., Meston, C. and Rosen, R. (2005) The Female Sexual Function Index (FSFI): Cross-Validation and Development of Clinical Cutoff Scores. Journal of Sex \& Marital Therapy, 31, 1-20. http://dx.doi.org/10.1080/00926230590475206

[22] Eaton, W., Muntaner, C., Smith, C., Tien, A. and Ybarra, M. (2004) Center for Epidemiologic Studies Depression Scale: Review and Revision (CESD and CESD-R). In: Maruish, M.E., Ed., The Use of Psychological Testing for Treatment Planning and Outcomes Assessment, 3rd Edition, Lawrence Erlbaum, Mahwah, 363-377.

[23] Bradley, C.S., Rahn, D.D., Nygaard, I.E., Barber, M.D., Nager, C.W., Kenton, K.S., Siddiqui, N.Y., Abel, R.B., Spino, C. and Richter, H.E. (2010) The Questionnaire for Urinary Incontinence Diagnosis (QUID): Validity and Responsiveness to Change in Women Undergoing Non-Surgical Therapies for Treatment of Stress Predominant Urinary Incontinence. Neurourology and Urodynamics, 29, 727-734. http://dx.doi.org/10.1002/nau.20818 